\title{
Use of Social Media to Manage Crises: a Case of Daystar University's 2017/2018 Crisis
}

\author{
Mavis Eleanor Manyasa, Daniel Onyango Omondi, Dr. Ruth Owino, Dr. Daniel Robert \\ Aswani* \\ School of Strategic and Organizational Communication (STOC), Daystar University
}

*Corresponding Author: Dr. Daniel Robert Aswani, School of Strategic and Organizational Communication (STOC), Daystar University

\begin{abstract}
Social media has revolutionized the way we communicate. For that reason, communicators cannot dowithoutit. The nature of communication on social media platforms demands instantaneous messaging that befitsthequestoftheconsumers. Communitiesonsocialmediaexertpressureoncommunicators to satiate their communication needs. This pressure is felt most when organizations are facing crisis. Aspects of the crisis become trendy and corporate communicators need to address the issues raised in the trendy topics create need that has to be addressed by the communicators. It is the nature of communication on social mediathatmakesastudycontextualizedinacrisisbothurgentandnecessary. Today, organizations cannot speak about crisis communication to the exclusion of social media. How social media was used in the Daystar university2017/2018crisishelpsteaseout some of the considerations that corporate communicators can look out for as they seek to handle crisis communication in a reloaded manner. The findings speak to the staggered adoption of social media in crisis communication and highlights the need for organizations to take a negotiatedapproachthathelpsorganizationsbeflexibleandmeettheexpectationsofpublics.
\end{abstract}

\section{INTRODUCTION}

Daystar University faced a difficult period during the 2017/2018 crisis which was a serious check on how the university incorporated the lessons from the crisis communication. The period was characterized by the heightened need to maintain mutually beneficial relationships with the university's publics. Crisis communication was propelled by increased use of social media. The way the university was to conduct itself spoke to the integral concepts of servant leadership, integrity, excellence, quality customer services and effective communication that the university upholds (Daystar University, 2016).

In 2017, the university had to deal with many complaints against the then administration ranging from high tuition fee, misuse of funds, complacency of senior management, a culture of intimidation, broken hostels and facilities, students expected to use clinic (Ngina, 2017). Students preferred social media - as their communication channel to discuss the issues bedeviling the university. Social media helped heighten the issues in question and made the discussion about the crisis a trendy topic. The university management made the decision to close the university as students escalated the crisis by boycotting classes to compel the management to pay attention to students' grievances.

Daystar University's crisis and the place of social media well captures the findings of the Consumer Insight (2013), which captures the ages between 7 and 25 years as social media natives. Social media has been made easy using technological gadgets - gadgets that are increasingly being an extended part of the hand. The age bracket cited above will for a better part of the day have a phone or iPad/tablet in their hands. This being the case, students, and other publics perceived social media as a way to draw support from the wider public and thus guide discussion around the crisis. This situation accentuates Dabner's (2012) conclusion that social media, particularly Facebook and Twitter are the latest relationship interconnectors among learners.

Studies have described and theorized how well organizations need to manage crises and ensure the reputation of the organization (Page \&Fearn, 2005; Hill \& Knowlton, 2006; Ford, 2013).The arguments presented by these authors suggest a model where information was disseminated through broadcast and print media. The reality of social media speaks to the disruptions that dissemination of 
information can be done today. Faster communication has made crises communication a touch of a button. Social media has adversely altered crisis communication conditions, the platforms have enabled crises to spread and develop differently (Veil, Buehner, \& Palenchar, 2011). For Daystar University, the crisis was amplified, analyzed and shared widely thanks to social media. To this end, social media can be used to disapprove and confront establishments and their response strategies to crises (Wendling, Radisch, \& Jacobzone, 2013).

Social media platforms can be exploited to aid an organization communicate the crisis successfully (González-Herrero \& Smith, 2008). The platforms have allowed everybody to be a source of information, allowing users to share views, perceptions, and familiarities with others (Marken, 2007). Despite these citations, social media platforms pose new challenges for crisis communication and management. The use of social media in crisis communication thus becomes vital for the corporate communicator. For instance, the platforms allow free flow of information, this is very crucial as the chances of reputational risks have been heightened (Kaul et al., 2015) and thereby calling for communication managers to aptly respond to issues raised. Further, communication practitioners must ensure that messages are relayed to the different stakeholders in a manner that helps address concerns prior to, during and after a crisis. Even with its potency, scanty literature addresses how social media can be used to harness information and end disruptive crises for institutions. This paper examines how social media was used in managing the 2017/2018 Daystar University crisis.

\section{MeTHOdOLOGY}

The study adopted a descriptive survey as its research design. A descriptive research design gives an account of the situation as it is (Kothari, 2004). Descriptive research aids in identifying the features of a group in a given situation, it assists in giving logical thinking about characteristic of a given situation. The total population for the study was 4606 students - undergraduate and postgraduate students (Daystar, 2019).There are 280 teaching and non-teaching staff. The target population was 3935 undergraduate students from Daystar University and the 12 staff from the Corporate Affairs department. Arising from the population, the researchers drew 120 students and 4 staff from the Corporate Affairs Department. The sample was drawn using the stratified random sampling based on the schools within the university as schools provided homogeneous units within the university (Kothari, 2004).

The study generated primary data and secondary data. Some of the information was collected firsthand from the sources while other data was generated from previous studies. Specifically, the researchers used questionnaires and interviews to collect primary data. For the distribution of questionnaires to the undergraduate students, the researchers trained three research assistants on the method the research would use to identify and administer the questionnaire to the target audience the research was aimed at collecting data from. Of the three research assistants two were assigned to collect data from Athi River Campus and one was assigned to Nairobi Campus. Athi River campus was assigned two research assistants since geographically the campus is bigger and the classrooms are scattered thus adding a challenge is distributing of the questionnaires. Further, the researchers and the research assistants worked hand in hand with school administrators from the five schools (the strata) in Athi River Campus who assisted in identifying the class schedules for fourth year students. The researchers purposively selected fourth year students because they were second year students during the crisis at the institution. Research assistants were assigned the duty to collect data. Questionnaire was selected for this study because of its ability to collect significantly large quantities of data from respondents within a limited time and resources. In-depth interviews were ideal as the researcher's desired sample consisted of a very specific target population. The interviews were used to acquire information on the social media strategy used by the university during the crisis and how crisis communication was managed at the institution. The technique is advantageous as the researcher gets a good response rate and in-depth feedback (Cooper \& Schindler, 2003). The shortcoming of this method was that it was time consuming, could have been biased (Cooper \& Schindler, 2003).

Data analysis is the process of making sense out of text and image according to (Creswell, 2009). For quantitative data, the Statistical Packages for the Social Sciences (SPSS) version 20.0 software was used in analyzing quantitative data. Qualitative data generated through the interviews was analyzed thematically. The researchers settled on thematic analysis since it was adaptable and can be used in any theory (Braun \& Clarke, 2006). The researchers were kin to look out for keywords and patterns equivalent to the presentation of quantitative data. 
Ferrell, Freaedrich, and Ferrell (2008), argued that research ethics accentuates on saying what is right and wrong in the research period. Researchers ensured that the study adhered to the correct process in the gathering and evaluation of data and recommendation of the research outcomes. We secured approval from the Daystar University Ethics Research Board (DU-ERB) and the National Commission for Science, Technology, and Innovation (NACOSTI) before going to the field to collect data. An introductory letter for data collection was obtained to enable the researchers to collect the data from Daystar University staff and employees. We avoided bias during data analysis and interpretation. In adhering to the ethical standards such as objectivity and the avoidance of selfdeception, the researchers were able to secure the confidence of students to participate in what was going to be a difficult task of getting feedback from students. We also allowed respondents to drop off at any point during the data collection process. Over and above the fact that we had to seek voluntary participation of the respondents. The researchers ensured that the identities of the respondents were protected by not including a name section in the data collection tools and not quoting the respondents during the presentation of data and findings.

\section{FINDINGS}

Of the 120 questionnaires that were distributed to undergraduates in the six different schools at Daystar University, 118 were appropriately filled and returned giving a response rate of $91.5 \%$. The respondents were almost an equal representation with males contributing $45 \%$ while female respondents were 54\%. A majority of the respondents were aged between 18-25 years (89.8\%) with a paltry percentage of those above 26 years $(10.2 \%)$. Respondents indicated that they had subscribed to multiple social media networking sites including: Flickr (5.1\%); Looper man and WhatsApp (22\%); LinkedIn (36.4\%); Pinterest (44.9\%); Twitter (67.8\%); Facebook (70.3\%); YouTube $(82.2 \%)$ and Instagram (89\%). The data is presented in figure 1.1 below.

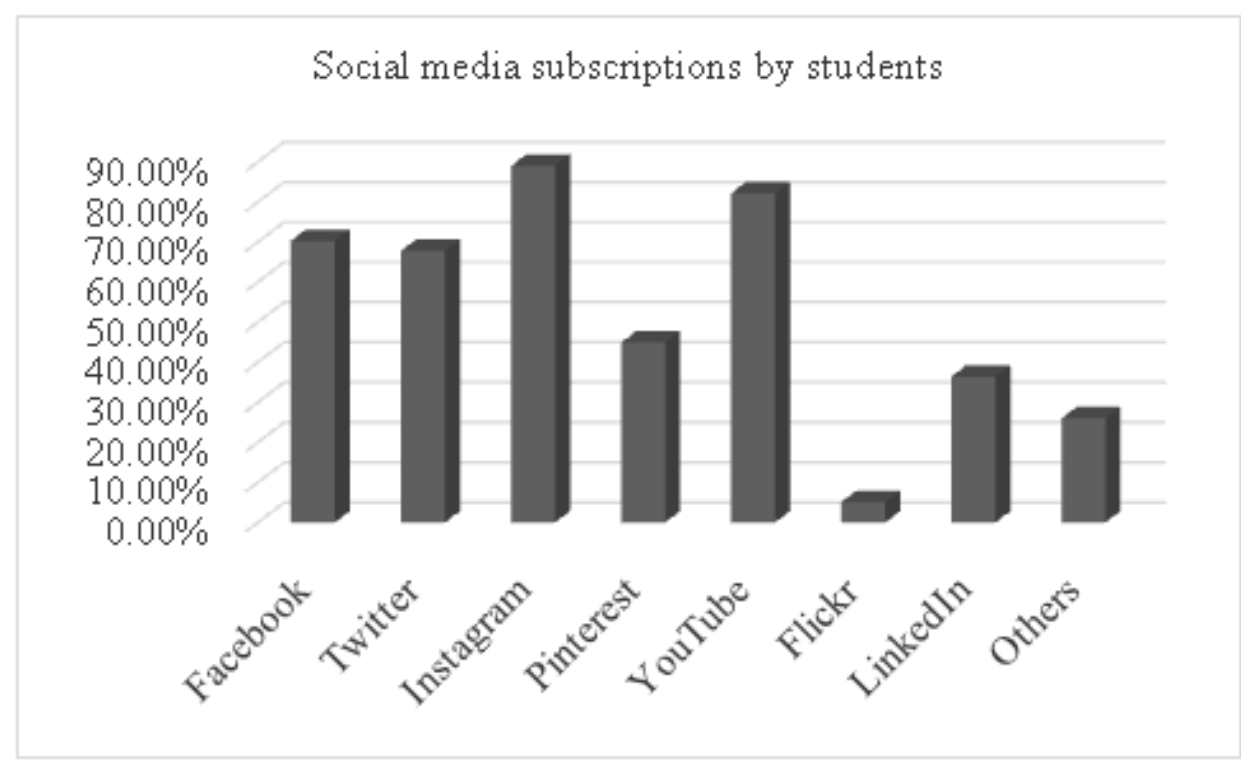

Figure 1.1. Social Media Subscriptions by Students

Daystar University had similarly subscribed to many social media networks. From the in-depth interviews, the study established from respondent Corp/1/2/2019 as follows:

The institution is subscribed to Facebook, Twitter, Instagram, WhatsApp, LinkedIn and the school Website. These social networking sites are managed by five selected members from the Corporate Affairs Department. We have policies in place that govern how social media is handled and all the five members have undergone rigorous training on social media management.

Being a subscriber to some of the social media networking sites made it easy for the students and other publics to communicate and network with the institution. About one third of the respondents (30.4\%) did not subscribe to any Daystar University social media networking accounts. Of those who subscribe, $25 \%$ subscribed to all the university accounts. Other subscribed to Pinterest $(0.8 \%)$; LinkedIn (7.6\%); Instagram (23.7\%); Twitter (37.3\%); Facebook (42. 4\%); all Daystar University social media accounts $(25 \%)$. 


\subsection{Social Media Sites Used by the Respondents During the Student's unrest}

The study findings revealed that respondents used different media during the Daystar University crisis. Of the respondents who used YouTube and LinkedIn were $1.7 \%$ each; while those on Instagram 7.6\%. Facebook and Twitter attracted the highest number of students who posted about the unrest at $14.4 \%$ and $20.3 \%$ respectively. About $6.8 \%$ of the respondents indicated that they posted on other social networking sites naming WhatsApp and Telegram as some of the other platforms. The other $57.6 \%$ of the respondents indicated they did not post anything on any social media concerning the unrest. Figure 1.2 shows the social media sites used by the respondents during the 2017/2018 unrest.

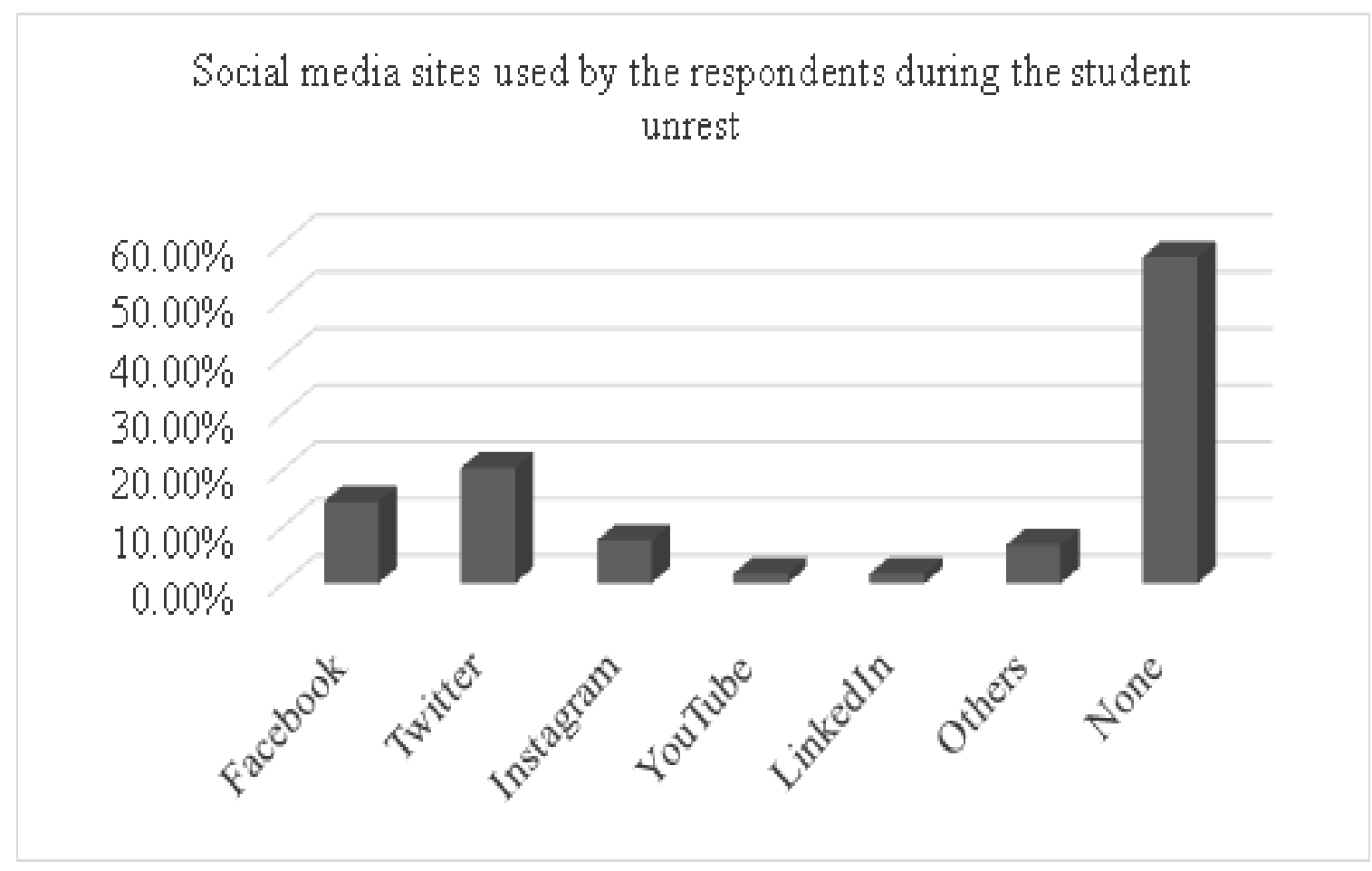

Figure 1.2. Social Media Sites used by the Respondents During the Unrest

The above finding is an indication that during the crisis, majority of the students at Daystar University did not post about the unrest on social media, despite the crisis being escalated on social media. The findings further reveal that, during a crisis, not all the respondents used social media to paint the university's reputation negatively, it could be argued that some social media users who posted negative comments may have been individuals who were not Daystar University students. Findings from the interviews, revealed that the university used social media platforms to communicate with the students at the time of the crisis. Respondent Corp/1/2/2019 revealed that at the outset of the crisis, the institution used Facebook to communicate as follows:

We put out some posts on Facebook regarding the strike, this was guided by a prior social media evaluation that revealed the social media site had a larger audience, and thus the communication would reach a bigger audience.

However, the study found out that during the crisis the institution halted their communication via social media when the comments became negatively overwhelming. Therefore, this means that the institution partially used social media as a communication channel during the crisis.

\subsection{Evaluation of Daystar University's Social Media Usage}

The findings indicated that $13.6 \%$ were satisfied with how the institution used social media while $61.8 \%$ were dissatisfied with the University's usage of social media during the crisis. However, $1.7 \%$ of the respondents chose not to respond to the question and $22.9 \%$ of the respondents chose to remain neutral. These findings mean that a majority of the respondents were not content with how the institution handled the crisis on social media, the crisis communication was not timely, it was inadequate and ambiguous. Figure 1.3 shows the evaluation of Daystar University's social media usage in terms of frequency, clarity, and speed of communication during the unrest. 


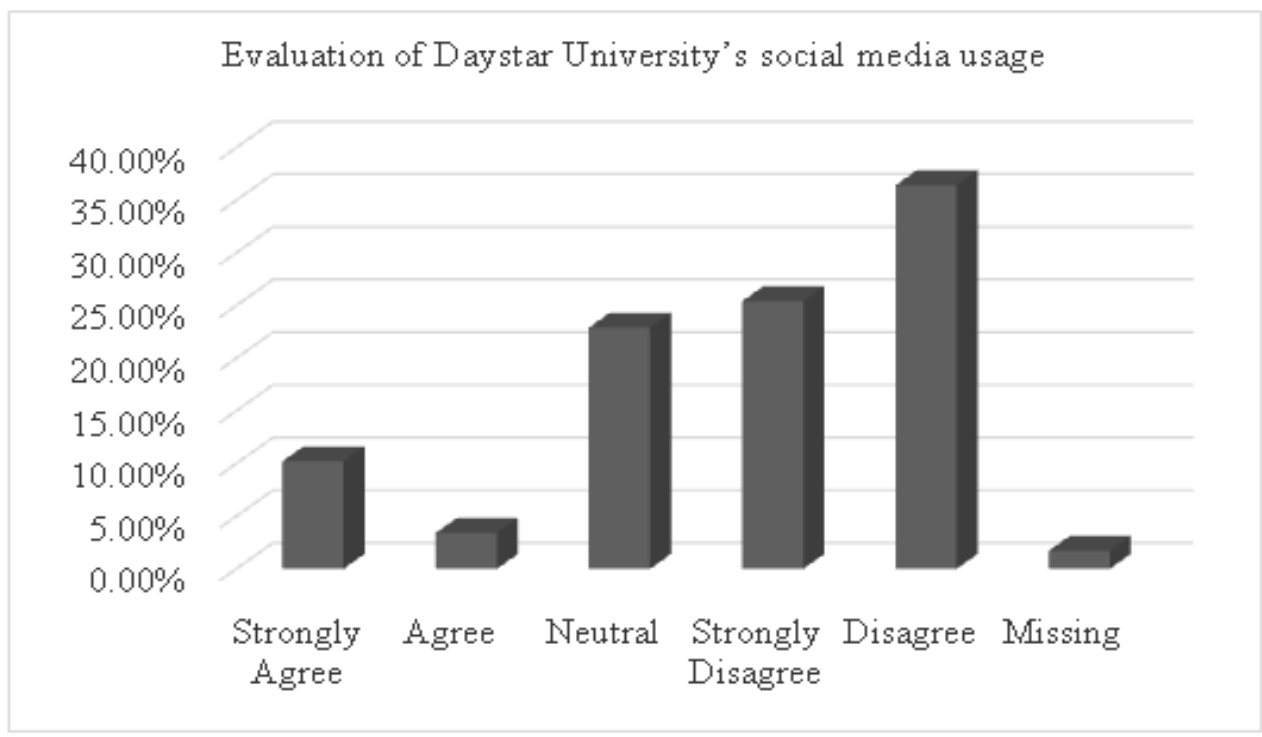

Figure 1.3. Evaluation of Daystar University's Social Media Usage

Data findings from the In-depth interviews revealed that the university did not disseminate information on social media with great speed and neither did they give out constant updates on the social networking sites. Respondent Corp/1/2/2019 acknowledged that the reason for not communicating constantly via social media was because the social media plan at hand had to change. The response was as below:

Our plan for social media, during the crisis, initially involved us simply sending out messages to try calm the students down and assure them that the situation was under control, but the moment we sent out the positive messages, all we received were insults, and questions concerning the grievances raised, and since the school was still in a stage where they were trying to figure out how to solve the situation, we really did not have much information to rely.

Respondent Corp/2/2/2019 added as follows:

The messages we were sending out were clearly not what the students wanted to read or hear. We thus opted to not post on the social media platforms Facebook and Twitter which we had initially resorted to and we further went on to deleted some of the posts we had put out because they were being shared countless times and reaching large masses of people.

Respondent Corp/2/2/2019 statements further, corroborated with what Respondent Corp/1/2/2019 had said by stating as follows:

We tried to have conversations online and tell the students that the institution had the matter under control, but these approaches did not seem to work for us. The students had set their minds on what they wanted, hence everything we tried backfired.

These findings mean that Daystar University was not prepared to handle the crisis and to incorporate social media in their crisis communication strategy. The use of social media during the crisis is vital in managing information during a crisis, therefore, crisis managers should select the most appropriate strategy and channels to protect the reputation of an organization.

\subsection{Social Media Usage in Addressing Student Grievances}

When asked to evaluate Daystar University's response strategy to the grievances posted on social media, the findings indicate that $49.1 \%$ of the respondents strongly disagreed that the University responded to their grievances. $20.3 \%$ of the respondents agreed that their grievances were addressed, $1.7 \%$ of the respondents chose not to respond and $28.8 \%$ of the respondents chose to remain neutral. The findings can be interpreted to mean that most of the respondents felt that the response of social media was dissatisfactory, thus social media strategy used by the institution at the time of the crisis was not effective. Figure 1.4 shows findings on how social media was used in addressing students' grievances. 


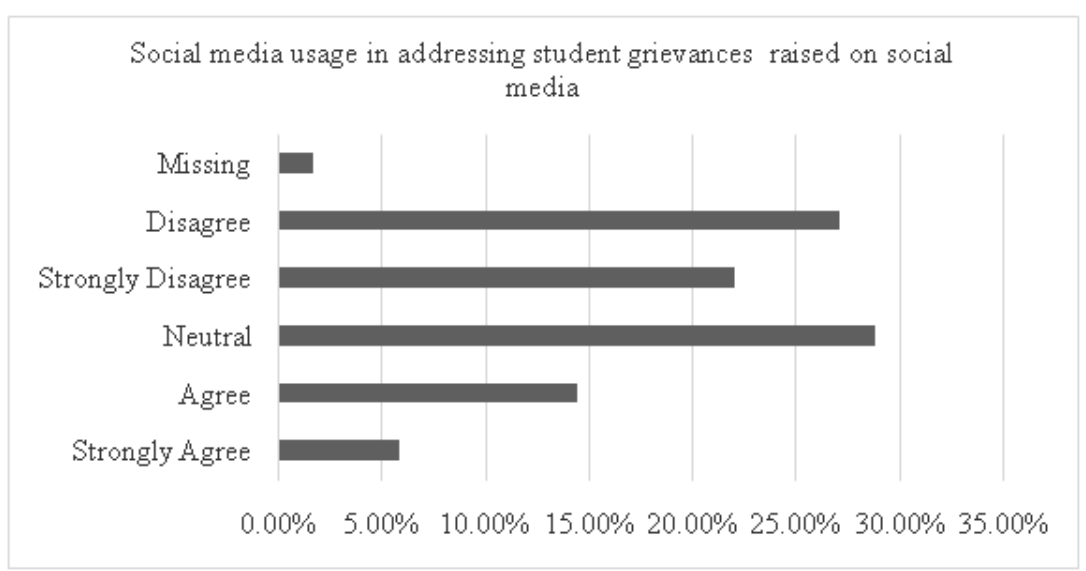

Figure 1.4. Social Media Usage in Addressing Students' Grievances

Further, Respondent Corp/1/2/2019 revealed that the institution opted not to respond to the student's grievances on social media as they deemed the issue as an internal issue. The response was as indicated below:

During the crisis, we monitored the posts that were being shared on social media and noted that some individuals who were propelling the hashtags were not Daystar University students, and since the issue was between the students and management, we opted to solve the issue in house. It was very challenging to try and get the students to engage in dialogue as they were fixated on instant solutions.

Respondent Corp/2/2/2019 further corroborated this by stating as follows:

It was management vs students' issue and not with the other publics on social media, the students were fighting the management and the institution did what it did to protect the students. We opted to address the issues in house, through meetings and using emails and memos to communicate our stand on the strike and what we were doing.

The above findings imply that the university was aware of the impact of the information and conversations that arise from social media would have on the reputation of the university.

\subsection{Evaluation of the Social Media Usage by Daystar University}

When asked whether the university used social media during the 2017/2018 crisis to engage students, $54.2 \%$ of the respondents disagreed and $25.5 \%$ of the respondents agreed. However, $18.6 \%$ of the respondents chose to remain neutral while $1.7 \%$ chose not to respond to this question. Majority of the respondents were not satisfied by the university's engagement on social media, since they presented their grievances on social media, but they did not receive feedback through the same channels. The finding corroborated by findings from the in-depth interviews which reveal that the organization, at the onset of the crisis did not have a social media strategy for the crisis. Figure 1.5 shows the evaluation of the university's usage of social media during the crisis.

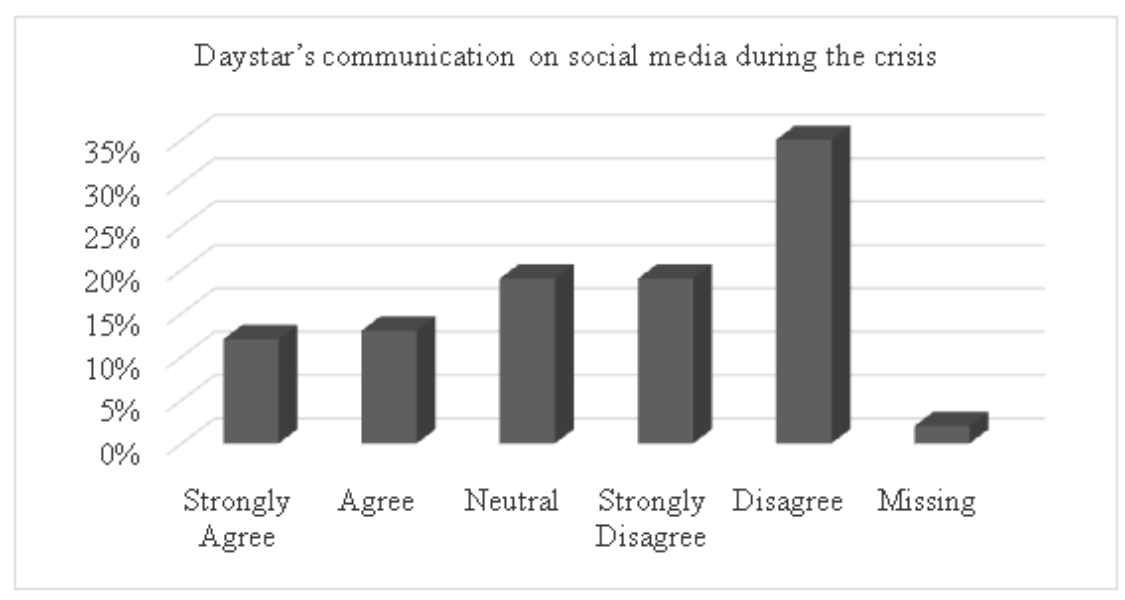

Figure 1.5. Daystar University's Communication on Social Mediain the Crisis 
The response from Respondent Corp/3/2/2019 is stated below:

We had to develop a social media strategy during the crisis, but it was also quite countered by the student body. But as days went by, the responses on social media became overwhelming, we responded with positive messages, which beseeched the students to be patient as we tried to gather facts and solve the issue internally and not necessarily responding to the negative comments about the school, but in time we gave up as the negative comments were overwhelming. "Many times, we pulled down messages to reduce the avalanche of countering messages which worsened the crisis in the public eye. Despite these, we noted where information was not readily available and took the issues to closed door discussions with student leaders who had spearheaded the crisis.

These findings can be interpreted to mean that in crisis, the organization needs a social media strategy to guide in managing the situation. This is because when an organization does not communicate or respond to the stakeholders concerns it in turn creates negative publicity. As much as it may not be possible to respond to all the comments or control what is being said on social media, it is important that the organization show empathy to the stakeholders instead of deleting negative comments or concerns raised. The act of deleting may create a perception of deceit, lack of transparency and no concern, resulting to credibility issues.

\subsection{Evaluating the University's Communication on Social Media During Crisis}

About $40.7 \%$ of the respondents disagreed, $31.3 \%$ agreed, while $27.1 \%$ remained neutral and $0.8 \%$ of the respondent did not respond to the question. Majority of the respondents felt that at the time of crisis, the university did not have enough neither did it meet their expectations. The interviews findings reveal that the institution had most of the information that their stakeholders needed regarding what the institution was doing in regard to managing the crisis and solving their grievances, but they were faced by a myriad of challenges including responses. The respondents were further asked if they considered the information shared on social media by Daystar University during the 2018/2019 crisis was sufficient. Figure 1.6 gives the findings to the question.

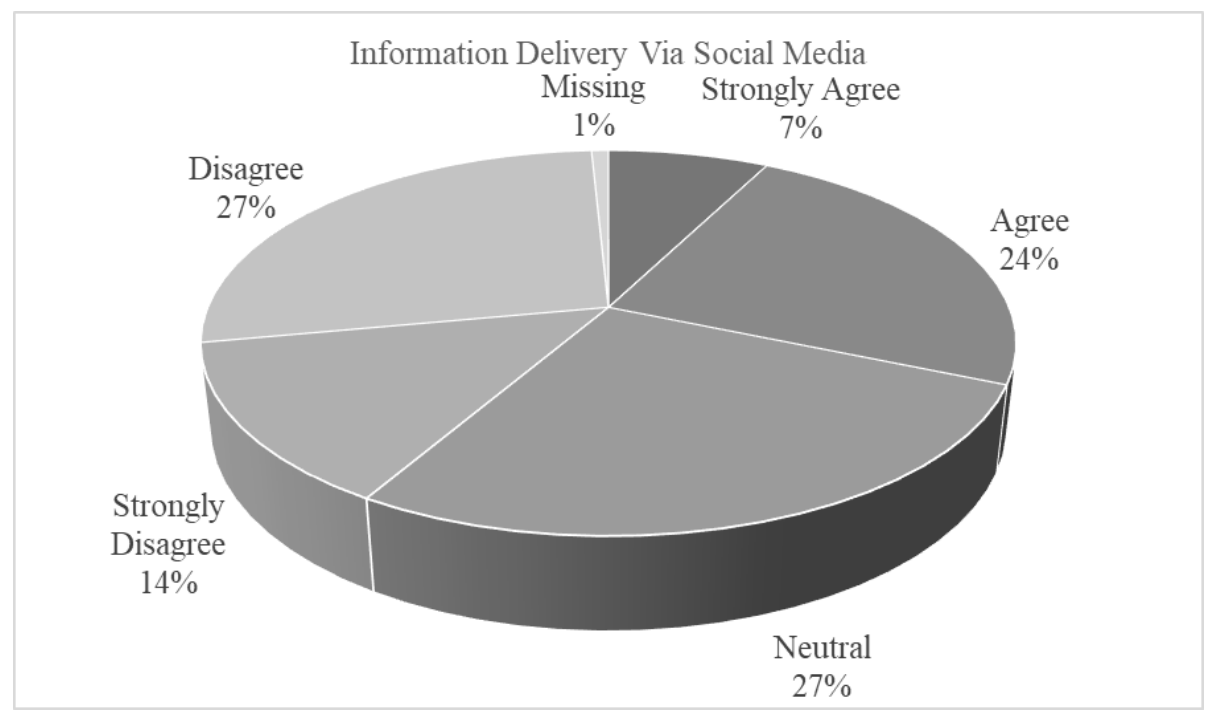

Figure 1.6. Information Delivery via Social Media

Respondent Corp3/2/2019 stated as follows:

The challenge came about with the distilling of the messages in the absence of appropriate responses to the questions that followed the messages which were posted, and further adapt these to the different media channels.

Despite the corporate affairs confession that they were in possession of the information needed by their stakeholders, they did share it on their social media platforms being prepared with information to share with their stakeholders, the institution was not only unprepared to respond to the questions that were raised by the students, the numbers of concerns raised where overwhelming for the institution. 


\subsection{Evaluation of Daystar University Properly Managed the Social Media Crisis}

When asked if they were confident in the way Daystar University managed the crisis on social media in the 2017/2018, $57.6 \%$ of the respondents disagreed with this statement. $28.8 \%$ of the respondents indicated that they were confident in the way Daystar University managed the crisis on social media during the unrest while $10.2 \%$ chose to remain neutral while $3.4 \%$ respondents refrained from responding to this question. While most of the respondents (57.6\%) were not confident with the way Daystar University managed the crisis, a significant proportion of the student indicated they were confident with the way the university handled the students' unrest. This can be interpreted to mean that the students followed information on the crisis from multiple information outlets therefore increasing their confidence beyond the use of social media as a source of information. From the indepth interviews, the institution handled the crisis in the best way they could, it being the first time the institution was facing a social media fueled crisis. Figure1.7 shows the evaluation of Daystar's management of the crisis on social media.

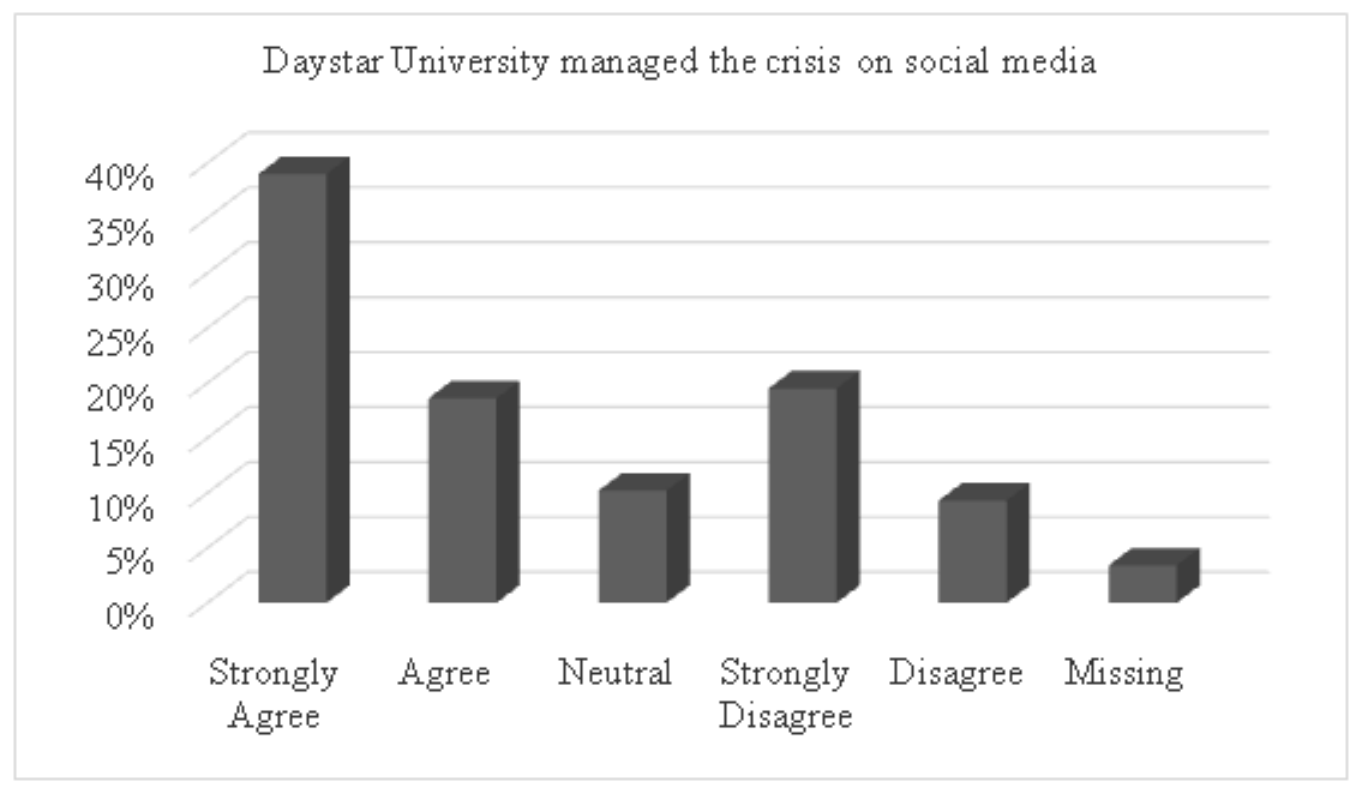

Figure 1.7. Daystar University Managed the Crisis on Social Media

Respondent Corp/3/2/2019 stated as follows:

The social media crisis was a learning curve for the institution, we had no prior experience in handling a similar situation and thus it was very challenging, it was however helpful because moving forward we have learned the importance of social media usage during a crisis.

Respondent Corp/1/2/2019 shared the same sentiments as Respondent Corp/3/2/2019 and stated as follows:

The scenario has also advised the University on how to manage social media even without a crisis. We are now very active and our posts on the platforms are now more intentional.

The findings imply that crises can spell out opportunities, for instance, learning opportunities on proper management practices and opportunities for stakeholder relationship building. It may also indicate that the university may have overlooked the importance of using social media during a crisis. Thus, organizations need to rethink their crisis management strategies so as to be well equipped in the event they are faced by a different or similar crisis. Because not handling crises properly subject an institution to various loses.

\subsection{Crisis Communication Management at Daystar University During the 2017/2018 Crisis}

The researchers also sought to find out how the university managed crisis communication during the 2017/2018 crisis. Data presented in this section was collected through in-depth interview with Respondent Corp/3/2/2019 who provided responses for the research question: How did Daystar University manage crisis communication during the 2017/2018 crisis? Findings from the interview 
gave the researchers insights on how the institution handled the crisis communication during the 2017/2018 crisis.

Respondent Corp/3/2/2019 reveals that the institution developed a crisis communication plan that was designed to be used during the crisis. Despite having a crisis communication plan, a social media strategy was distinctively missing. The institution however used the social media platforms, Facebook, Twitter, WhatsApp, LinkedIn, Instagram, and the institutions website as feedback channels.

Respondent Corp/3/2/2019 stated as follows:

We used these and continue to use them to monitor what stakeholders are saying for both anticipation, prevention, and response.

This finding indicates that the University took the appropriate steps in dealing with a crisis by having a crisis communication plan in place to deal with the event. Further the respondent reveals that after receiving a list of all the student's grievances between the months of September and October 2017, at a student meeting with VC and Management at Nairobi Campus. The grievances were compiled and the institution prepared response and communication on the grievances. The institution however did not immediately send out communication on the way forward or how they would handle the situation. This finding implies that the institution could have been gathering and vetting the facts before they could communicate anything to their students. However, the lack of response and action from the institution resulted in the boycott of classes and the social media campaign by the students to try and probably get a reaction from the institution. This finding reveals that a lack of fast response can further the crisis as the stakeholders feel ignored and resort to seeking crisis information elsewhere. The information they get from other sources may anger them further and result to an organization damaging its reputation.

The respondent further revealed that the institution proceeded to form a Crisis Management Team (CMT) on $18^{\text {th }}$ November 2017, the team comprised of the Vice Chancellor (VC), School Deans, Corporate Affairs manager, Public Relations Officer and they further hired a Crisis Communication Specialist. The team was tasked with planning on how to mitigate the crisis and advising the senate and the Ag. VC throughout the crisis. This finding means that the institution knows the value of a CMT and its ability to assist in deciding actions and developing strategies to mitigate a crisis swiftly. The respondent also revealed that the institution took a step to identify different spokespersons to communicate with different stakeholders and donors. The VC, or an individual that the VC designates, was selected as the spokesperson for the stakeholders in Kenya, the VC was also the spokesperson for Daystar University in the United States. The executive director of Daystar University in the United States was chosen as the spokesperson for the donors in the United States. This finding could be interpreted to mean that the institution was prepared to disseminate crisis information to their stakeholders and thus the selection of spokespersons.

The respondent additionally reveals that the CMT struggled to handle the crisis that the institution was facing because of the lack of trust by the students in the administration. Respondent Corp/3/3/2019 stated as follows:

The VC and the Council Chair who were both caught up in the middle of the crisis allegations however made it strenuous for the institution to select an authority to respond to issues that were under investigation". Addressing staff, students, parents, and media satisfactorily did not effectively take off until the appointment of Ag. VC on 18th December 2017.

This finding reveals the challenges that arise when the leadership of an institution is accused of being responsible for a crisis. Studies have shown that organizations should not keep an individual onboard if potential damage outweighs value. This means that Daystar University could have taken the steps to remove the accused from the frontline of crisis management as they conducted investigations and managed the crisis. This also highlights the importance of trustworthy leadership during crisis management. The institution further put up notification and monitoring platforms which included the platforms included Facebook, Twitter, LinkedIn, WhatsApp, among others. Respondent 3/2/2019 stated as follows: 
We used these channels to monitor what stakeholders were saying for both anticipation, prevention, and response. We also used some limited recorded messages. However, we did not prepare any holding statements ahead of the crisis.

This finding implies that social media sites are important during a crisis as they help to inform an organization on how to manage the issues. Messaging was also a challenge for the institution, as respondent Corp/1/2/2019 indicated as follows:

Although we knew the type of information most of our stakeholders needed, it was difficult to distill key messages in the absence of appropriate responses to the questions asked.

Therefore, this may have contributed to the crisis escalating further as those affected by the crisis were not receiving any information from the institution. In a crisis, messages are considered vital as they help in distributing correct information and helps bridge the gap between what the stakeholders know and what they need to know from the organization.

Daystar University communicated with the key stakeholders using the institution's email addresses, emails were sent out to the students, and memos were also put on the notice boards. Most of the emails can however only be traced to 2018. Finding could be interpreted to mean that there was a deficiency of communication to the students concerning the crisis. In December of 2017, the institution sent out a memo to stakeholders on the decisions to send the VC on a sabbatical leave and to announce the appointment of the Deputy Vice Chancellor as the Ag. Vice Chancellor.

The institution also announced that it had launched investigations into the crisis and were expecting a forensic report by February 2018. The communication was done through memos that were sent to the students via email. The institution further sent press statements and briefings announcing the closure of the university. An email to all students and university community on the same announcement was similarly sent out by the institution. This was the second time the institution was being closed indefinitely. Therefore, this finding implies that a crisis is bound to reoccur if it was not resolved and if there exist any misunderstandings between those involved in the earlier crisis.

Findings from respondent/3/3/2019 reveal that it was after the VC was placed on sabbatical leave that proper crisis management kicked off. Respondent/3/3/2019 stated as follows:

A forensic investigation was commissioned immediately to look into the claims that had been brought forward by the students, this information was disseminated through school emails to the students.

The respondent further revealed that consistent communication from the university started in 2018 after the second closure of the school and the institution used Infospot (The University newsletter) social media, public announcements on local dailies, press releases and press briefings in an effort to reach all their stakeholders. The findings imply that the university was under pressure because they had been forced to close the institution twice. It also implies the university changed their communication plan, because after the second wave of the crisis is when the institution focused more on public communication, where they included more communication channels and messages as opposed to when the crisis began. For instance, the information on the formation of the taskforce was done through a newspaper, social media, and the school magazine.

Respondent/3/3/2019 further stated as follows:

The Company Board met and announced the appointment of a special taskforce to review the Forensic report, to reopen schools and investigate crisis and make recommendations to Trustees.

Findings reveal that the institution opted for dialogue as a way of managing the crisis at the institution. The institution held various dialogue sessions between the conflicting parties in order to better understand the crisis.

\section{Discussions}

From the findings, it was evident that a vast majority of respondents aged 18-25 years subscribed to social media sites among them Instagram, Facebook, YouTube, and Twitter. The student demographic showed an age group so attuned to social media as has been projected by DeCosmo (2019). Daystar 
University too had subscribed to similar social media sites, and this enabled a conversation prior to, during and after the 2018/2019 crisis. At the time of the crisis, most students were actively following the Daystar University social media accounts. This finding is supported by Coombs and Holladay (2012), who emphasize that a social media platform that reaches your target audience creates value during a crisis. However, as the crisis escalated, Twitter was adopted as a communication platform confirming that the University may have noted the blunder in the first wave and corrected themselves. Twitter has been stated to be the most appropriate platform to use during a crisis as it provides faster responses and enables immediate feedback (Apuke \& Tunca, 2018). This study thus showed the importance of selecting an appropriate social media channel to use in case of a crisis and the general importance of organizations using appropriate social media sites in their crisis management. It is important that institutions of higher learning harness the digital space and utilize the avenue on social media to actively communicate with their publics. Of the students who followed the Daystar University social media accounts, most of them were troubled with the rate of response from the university as there were no responses and updates on what was transpiring. It would be argued that Daystar University did not use social media effectively and thus reach as many publics who had followed the university's social media sites. It was perceived that apt preparation on the use of social media during the crisis would have helped build a favorable response that would have helped the university return a favorable reputation. By the time the university picked the use of the social media, it was to monitor the prodromes presented during the later phase of the crisis.

Through the interviews, it was suggested that the university should have used a WhatsApp number for communication purposes noting that this was a popular social media tool that each student could access. According to the students, the WhatsApp option provided a better option compared to the use of emails which very few students accessed during the crisis.

Further findings revealed that the institution lacked a proper social media strategy for the crisis, therefore the researchers hold the views that the institution was not sufficiently prepared for the predicament. A social media strategy is a fundamental aspect of a communication strategy, it is a well thought out plan that involves time, budget and includes a set of goals and a plan of action by an organization (Crawley, 2018). Lack of a proper social media strategy during the crisis was proven by a lack of constant updates on the crisis, not responding to social media posts by students and the deleting of posts on the platforms in an attempt to stop the negative comments under their posts and prevent reputational damage.

Deleting of social media posts by an organization that is facing a crisis reflects poor handling of the crisis. Findings showed that the institution deleted some of the posts they had put up with an aim of ceasing the negative comments. However, the action reflected a lack of transparency from the institution. Lack of transparency may have cost the institution their credibility because during a crisis transparency is mandatory. In the case of Daystar University, withholding information from the students portrayed a lack of transparency. The importance of transparency and credibility is emphasized by Nikolaev (2010) who stated that an organizations management needs to respond and react rapidly; information has to be successfully managed and given out simultaneously to all affected parties, to encourage the sustainability of its credibility (Nikolaev, 2010). Therefore, the university should have selected an appropriate social media strategy that best suited their crisis from the six strategies recommended by Floreddu and Cabiddu (2016) to appropriately handle the crisis.

From the findings, the researchers concluded that the institution used the egocentric strategy in communication during the crisis. Organizations that adopt the strategy share information with their stakeholders through social media but at no point will they engage in conversation with them (Floreddu \& Cabiddu, 2016). The respondents however did not find the strategy appropriate as they indicated that they would have preferred if the interacted with their posts on social media. An ideal social media strategy would be a mix of Openness, Conversational and Secretive. Openness suggests that an institution in a crisis openly puts out communication about the crisis to their stakeholders, this would have displayed transparency on the institutions part. Conversational would also have been ideal, this strategy proposes that organizations reply to all remarks shared by customers to launch a dialogue and deal with any conflict. The strategy assists in quickly countering claims that are made online and can help in preventing a crisis from escalating (Floreddu \& Cabiddu, 2016). Since some crisis information can be sensitive, the secretive strategy would have been ideal as it allows an organization to reply to complains through other channels like emails or calling the distraught stakeholder to resolve the issues. 
Moreover, the lack of a social media strategy may have contributed to the escalation of the crisis on social media. Findings revealed that the comments made on social media which the institution termed as "noise" drowned the voice of reason and the students gaining full support of parents and student bodies from other universities who got involved in institutions crisis. The researchers opined that if Daystar University had a proper social media strategy, they would have been capable of containing the issues before getting out of hand.

\section{CONCLUSION}

From the study findings organizations need to develop an all-inclusive social media strategy to prevent stumbling and at worst, being entirely consumed by social media. Similar perspectives have been advanced by Owyang and Lovett (2010) although they do not consider the demographics of those in organizations. Increasingly, social media is an avenue that can spur an already bad situation and corporate communicators need to play in that space and give the adequate information. Yet before a crisis, it is imperative that corporate communicators consider using social media accounts to capture prodromes and utilize these prodromes to prepare key messages to the different stakeholders. This has been well captured by Jiang, Luo, and Kulumeka (2016). Importantly, social media discussions can help organizations arrest a pending crisis and maintain its reputation.

As suggested by Fearn-Banks (2007), it is imperative that learning institutions develop a robust social media strategy. The fact that the institution re-energized after putting out messages on Facebook that were positive and reassuring without directly addressing the crisis, showed clear elements of an accommodative response strategy as recommended in Coombs' SCCT. A study conducted by Modeus et al. (2012) emphasized that message content is an essential factor in successfully using the platforms during crises. Before posting any messages, online crisis managers ought to consider the publics who shall consume the information and their response to it. Messages put out by organizations are more likely to be accepted by stakeholders if their requests are honored, since communication is a two-way process (Coombs, 2007).

Findings from the study indicated that the number of negative posts put out on social media by the students and other online users made it difficult for the institution to respond. This has been noted as one of the downsides of utilizing social media during a crisis. Hundreds of online users can chime into discussions resulting in hundreds of comments which organization may deem hard to manage (Kaul et al., 2015). When handling social media crises, organizations need to have online presence to sufficiently engage with its clients. Argenti (2013) argued that this is to plummet the possibility of other stakeholder's opinions being swayed by the posts. The ability to engage the clients through the comments could be attributed to the presence of a proper social media plan.

The SMCM posits that during, before and after a crisis, there exist three kinds of publics who consume and create information on social media: the content creators who create communication that can be accessed by others; followers, those who follow the creators for information and the social media in actives that get the information from other sources, they are known to come to contact with the information indirectly (Jin \& Liu, 2010). Daystar University followed recommendations of the SMCM which stipulates that organizations should be aware of the different social media users during a crisis and be able to handle them accordingly. The institution being aware that the matter propelled further as a result of the followers, some of whom were not directly affected by the crisis resorted not to engage with them online and opted to send communication via other channels.

About dissemination of information and speed of response, by the institution, the students were of the opinion that the university did not handle the predicament well. Therefore, this could mean that the university was ill prepared for the crisis. The students hoped for timely and accurate information to be disseminated via social media, but this was not the case. This finding could be attributed to Daystar University not giving liberal stakeholders more attention. This finding is supported by Argenti (2013) who states that the strength of an organization's reputation is determined by how they manage their communication with their stakeholders. This may have contributed to some of the respondents perceiving the institution reputation negatively. Further, the findings confirm Ryschka et al. (2016) study which opined that speed of response was validated as being of great importance to the perception of reputation. This study therefore emphasizes the obligation to issue information on a timely basis. 


\section{REFERENCES}

[1] Apuke, O., \& Tunca, E. (2018). Social media and crisis management: A review and analysis of existing studies. EUL Journal of Social Sciences, IX (II), 199-215.

[2] Argenti, P. A. (2013). Corporate communication. New York, NY: McGraw-Hill.

[3] Braun, V., \& Clarke, V. (2006). Using thematic analysis in psychology. Qualitative Research in Psychology, 3(2), 77-101.

[4] Consumer Insights (2013). Consumer insights report. Retrieved from http://www.ciafrica.com/ eshop/index.php/reports-holla-kenya-2013.html

[5] Coombs, W. T. (2007a). Ongoing crisis communication: Planning, managing, and responding. Thousand Oaks, CA: Sage.

[6] Coombs, W. T., \& Holladay, S. J. (2012). The handbook of crisis communication. Chi Chester, UK: Wiley-Blackwell.

[7] Cooper, D. R. \& Schindler, P. S. (2003). Business research methods (8th ed.). Boston, MA: McGraw-Hill Irwin.

[8] Crawley, C. (2018). Council post: A social media strategy is about more than just posting. Retrieved from https://www.forbes.com/sites/forbescommunications council/2018/03/13/a-social-media-strategy-is-aboutmore-than-just-posting/\#72a8edda47ca

[9] Creswell, J. (2009). Research design: Qualitative, quantitative, and mixed methods approaches. (4th ed.). Thousand Oaks, CA: Sage.

[10] Dabner, N. (2012). 'Breaking ground' in the use of social media: A case study of auniversity earthquake response to inform educational design with Facebook. The Internet and Higher Education, 15(1), 69-78.

[11] Daystar University. (2019). Daystar University catalogue (2017-2021). Nairobi, Kenya: Daystar University.

[12] DeCosmo, A. (2019). University president discourse after an on-campus crisis (Unpublished doctoral dissertation Philosophy). University of Northern Colorado. Boulder, Colorado.

[13] Fearn-Banks, K. (2007). Crisis communications: A casebook approach. London, UK: Lawrence Erlbaum Associates.

[14] Ferrell, O.C., Fraedrich, J., \& Ferrell, L. (2008). Business ethics: Ethical decision making and cases (6th ed.). Boston, MA: Houghton Mifflin.

[15] Floreddu, P., \& Cabiddu, F. (2016). Social media communication strategies. Journal of Services Marketing, 30(5), 490-503.

[16] Ford, T. (2013). Social Media and Crisis Communication: Theories and Best Practices (Unpublished master's thesis). Carleton University. Ottawa, Ontario.

[17] Gonzales-Herrero, A., \& Smith, S. (2008). Crisis Communications Management on the web: How Internet-Based technologies are changing the way Public Relations professionals handle business crises. Journal of Contingencies and Crisis Management, 16, 143-153.

[18] Hill \& Knowlton, (2006). Return on reputation: Corporate reputation watch. Retrieved from http:// www.hillandknowlton.com

[19] Jiang, H., Luo, Y., \& Kulemeka, O. (2016). Social media engagement as an evaluation barometer: Insights from communication executives. Public Relations Review, 42(4), 679-691.

[20] Jin, Y., \& Liu, B.F. (2010). The blog mediated crisis communication model: Recommendations for responding to influential external blogs. Journal of Public Relations Research, 22(4), 429-455.

[21] Kaul, et al., (2015). Social media: The new mantra for managing reputation. Vikalpa, 40(4), 455-491.

[22] Kothari, C. R. (2004). Research methodology: Methods and techniques (2nd ed.). New Delhi, ND: New Age.

[23] Marken, G.A. (2007). 'Social Media .. . The hunted can become the hunter'. Public Relations Quarterly, 52, (4), 9-12.

[24] Modeus, G., Paulsson, R., \& Olsson, H. (2012). Crisis management in social media (Master's thesis). Linnaeus University. Vaxjo, Sweden.

[25] Nikolaev, A. G. (2010). Thirty common basic elements of crisis management plans: Guidelines for handling the acute stage of "hard" emergencies at the tactical level. In W. T. Coombs, \& S. J. Holladay (Eds.). The handbook of crisis communication. (pp. 261-281). Chichester, UK: Wiley-Blackwell.

[26] Ngina, F. (2017). Nine reasons why Daystar University students have gone on strike. Ureport-Citizen Journalism. Retrieved from https://www.standardmedia.co.ke/ureport/article/2001260408/nine-reasonswhy-daystar-university-students-have-gone-on-strike. 
[27] Owyang, J., \& Lovett, J. (2010). Social Marketing Analytics. Retrieved from http://www.slideshare. net/jeremiah_owyang/altimeter-report-social-marketing-analytics.

[28] Page, G \& Fearn, H. (2005). Corporate reputation: What do consumers really care about? Journal of Advertising Research, 45(3), 305-313.

[29] Ryschka, A., Domke-Damonte, D., Keels, J., \& Nagel, R. (2016). The effect of social media on reputation during a crisis event in the cruise line industry. International Journal of Hospitality \& Tourism Administration, 17(2), 198-221.

[30] Veil, S. R., Buehner, T., \& Palenchar, M. J. (2011). A work-in-process literature review: Incorporating social media in risk and crisis communication. Journal of Contingencies and Crisis Management,19(2), 110-122.

[31] Wendling, C., Radisch, J \& Jacobzone, S. (2013). The use of social media in risk and crisis communication, OECD Working Papers on Public Governance: OECD.

Citation: Dr. Daniel Robert Aswani, et.al. "Use of Social Media to Manage Crises: a Case of Daystar University's 2017/2018 Crisis". International Journal of Media, Journalism and Mass Communications (IJMJMC), vol 7, no. 2, 2021, pp. 32-45 doi: http://dx.doi.org/10.20431/2454-9479.0702004.

Copyright: (C) 2021 Authors. This is an open-access article distributed under the terms of the Creative Commons Attribution License, which permits unrestricted use, distribution, and reproduction in any medium, provided the original author and source are credited. 